ISSN 0001-6002/2009/51/4/213-214 Acta Médica Costarricense, (C2009 Colegio de Médicos y Cirujanos
Miembro del Comité Editorial AMC, Inmunóloga pediatra, Universidad de Costa Rica. Hospital Nacional de Niños "Dr. Carlos Sáenz Herrera". Caja Costarricense de Seguro Social.
El Ángulo del Investigador

\section{Consejos prácticos para escribir un protocolo de investigación}

\author{
Olga Arguedas-Arguedas
}

La pregunta de nuestros lectores: El Dr. Julio Jaén, jefe de Servicio y coordinador del Postgrado de Radiología del Hospital San Juan de Dios, solicita una síntesis con consejos prácticos para que los residentes puedan escribir sus protocolos de investigación.

Nuestra respuesta: A ellos dedicamos la presente entrega.

Tras formular la pregunta de investigación y realizar la respectiva búsqueda bibliográfica, se debe escribir el protocolo de investigación para que sea inscrito o aprobado por parte de un comité ético científico. La complejidad del protocolo de investigación es paralela a la del estudio que se pretende efectuar. En esta sección, y considerando que la mayor parte de los investigadores noveles y los médicos que siguen estudios de postgrado, elaboran investigaciones de carácter descriptivo, nos circunscribiremos a los consejos prácticos para escribir protocolos de este tipo.

Antes de escribir el protocolo es importante que el investigador consulte a su comité ético científico local sobre las guías para la estructuración de este. En los servicios asistenciales de la Caja Costarricense de Seguro Social, existen algunos formularios prediseñados y disponibles en la página: www.cendeisss.sa.cr/etica/bioinv.htm.

El protocolo de investigación es la expresión escrita de la planificación de esta; debe ser detallado, preciso y claro. Es el documento base para el investigador, por lo que debe haber sido preparado y aprobado por un comité ético científico ANTES de la ejecución del estudio. Un protocolo bien hecho se constituye siempre en la piedra angular para elaborar el manuscrito final.

En general, la estructura del protocolo de investigación incluye el título del proyecto, el propósito del estudio, las características de la población por estudiar, el diseño y los procedimientos, la evaluación riesgo / beneficio, las obligaciones financieras y los métodos de compensación, la identificación de los participantes -incluyendo modalidad de reclutamiento-, y la obtención del consentimiento informado, los datos de los investigadores, las consideraciones relacionadas con los principios fundamentales de la bioética, la bibliografía y los anexos.

Recomendaciones sencillas para escribir cada sección:

1. Título: Debe ser breve, conciso, específico y ubicado siempre en espacio y persona (es decir, debe incluir el sitio donde se elaborará el estudio, la población y el periodo).

2. Propósito: Incluye la pregunta de investigación, el objetivo general y los objetivos específicos. Los objetivos se formulan iniciando con verbos en infinitivo, como describir, investigar, comparar, identificar, establecer, etc. El objetivo general se redactará con fundamento en la pregunta de investigación. Los objetivos específicos se plantean teniendo a la vista las variables incluidas en la hoja de recolección de datos. Los objetivos deben ser concretos, concisos, alcanzables, medibles y pocos. Para efectos de un estudio descriptivo, se recomienda proponer una cantidad aproximada de cinco objetivos específicos.

3. Características de la población por estudiar: Se describe la cantidad total de potenciales individuos o eventos por estudiar, así como los criterios de inclusión y exclusión. 
4. Diseñoy procedimientos: En los estudios observacionales o descriptivos, usualmente el diseño es muy sencillo y se fundamenta en la recolección sistemática de una serie de variables a partir de la hoja de recolección de datos. Esta recolección puede efectuarse de manera retrospectiva o prospectiva. Las fuentes de información son, por lo general, expedientes clínicos, registros electrónicos o grupos de reportes de laboratorio, gabinete o anatomo-patológicos.

La sección de diseño y procedimientos incluye un cronograma, donde los investigadores deben plasmar de manera realista, el estimado de tiempo que consumirá el proyecto desde su conceptuación hasta su finalización. Ej. diseño del proyecto: 2 meses, trámites de aprobación: 1 mes, recolección de datos: 6 meses, etc. Es recomendable expresar los periodos como unidades de tiempo (semanas, meses, años) y no como fechas, pues esto evita que el protocolo pierda vigencia.

No se debe omitir la inclusión de los instrumentos por utilizar para recolectar la información, así como el plan de análisis de los datos, contemplando también los paquetes estadísticos y otros detalles técnicos.

En general, en los estudios de carácter observacional el análisis estadístico se efectúa con base en los fundamentos de la estadística descriptiva. Así, lo usual es que se especifique que las variables cualitativas incluidas en la hoja de recolección de datos, serán presentadas como distribuciones porcentuales, y las variables cuantitativas, como alguna medida de tendencia central (usualmente promedios, con sus respectivas desviaciones estándares, o bien, medianas, con sus respectivos valores mínimos y máximos). En general, en la mayoría de los estudios descriptivos cabe la aclaración de que no se aplica ninguna técnica de muestreo, pues se incluyen todos los casos o eventos observados en el periodo de estudio.

5. Evaluación riesgo / beneficio: En los estudios de carácter observacional no suelen haber riesgos mayores. Tampoco existen beneficios directos para los individuos de quienes proviene el material de análisis (expedientes, registros, muestras o especímenes), sin embargo, el conocimiento científico que se obtendrá tiene un potencial beneficio para la colectividad.

Los investigadores deben manifestar por escrito su compromiso de salvaguardar la identidad de las personas que son fuente de origen de los datos.

5. Obligaciones financieras y compensación: Los estudios observacionales descriptivos, en su mayoría, carecen de fuentes externas de financiamiento, y lo usual es que los investigadores asuman los costos de estos. Sin embargo, en caso de existir alguna fuente proveedora de recursos para la ejecución de un estudio, esta debe identificarse en el protocolo, así como el monto o tipo de colaboración que brindará.
Las compensaciones a los participantes no son usuales en nuestro país, en estudios de carácter observacional.

6. Identificación de los casos y consentimiento: En los estudios observacionales descriptivos casi siempre los casos se identifican mediante archivos o registros. Con respecto a la pertinencia de aplicar un consentimiento informado, resulta útil recordar los siguientes elementos:

a) El consentimiento informado, para ser necesario, debe ser factible.

b) El consentimiento informado es obligatorio siempre que exista contacto prospectivo entre el investigador y el participante, para efectos de la investigación en curso.

c) El consentimiento informado $\mathrm{NO}$ se requiere para estudios retrospectivos basados en expedientes médicos o archivos.

7. Información de los investigadores: Contempla la declaración de potenciales conflictos de interés, si es del caso. En vista de que los comités ético científicos deben evaluar la idoneidad de los investigadores, tienen que incluirse el código y los atestados de estos.

8. Consideraciones bioéticas: Los investigadores deben manifestar por escrito que el estudio respetará los principios de autonomía, beneficencia / no maleficencia y justicia. Un comentario adicional sobre la aplicación de estos principios en estudios de carácter intervencional, se incluirá en una futura sección de esta revista.

9. Bibliografía: Las referencias consultadas para elaborar el protocolo deben citarse en orden de utilización, con un estilo uniforme y siguiendo la normativa vigente. En esta misma sección, en el número anterior de la revista, se presentó una orientación sobre la estructura de las referencias bibliográficas.

10. Anexos: Incluyen la hoja de recolección de datos y autorizaciones especiales, en caso pertinente.

En síntesis, el protocolo de investigación para un estudio observacional descriptivo debe ser un documento breve, equilibrado en sus secciones, y de calidad. Los errores más frecuentes en este tipo de protocolos son:

- Inadecuadas redacción y ortografía

- Ausencia de validez científica

- Objetivos generales y específicos incongruentes

- Defectos de formato (omisión de secciones, marco teórico excesivamente extenso)

- Uso incorrecto de recursos bibliográficos

Esperamos que esta entrega sea útil para producir un buen material científico. 